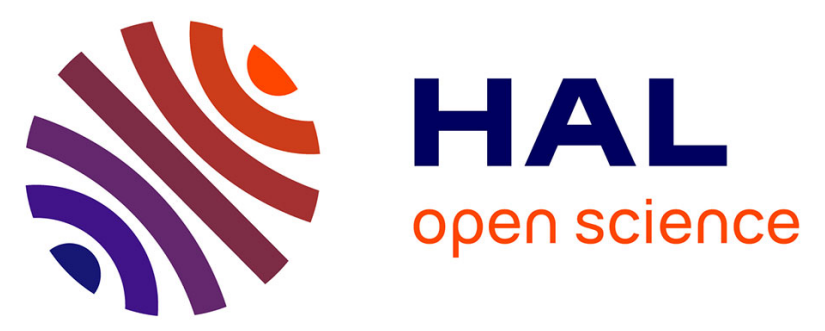

\title{
Architecture for Digital Spare-Parts Library: Use of Additive Layer Manufacturing in the Petroleum Industry
}

\author{
R. M. Chandima Ratnayake, Arvind Keprate, Roman Wdowik
}

\section{To cite this version:}

R. M. Chandima Ratnayake, Arvind Keprate, Roman Wdowik. Architecture for Digital Spare-Parts Library: Use of Additive Layer Manufacturing in the Petroleum Industry. IFIP International Conference on Advances in Production Management Systems (APMS), Sep 2019, Austin, TX, United States. pp.537-545, 10.1007/978-3-030-30000-5_66 . hal-02419250

\author{
HAL Id: hal-02419250 \\ https://hal.inria.fr/hal-02419250
}

Submitted on 19 Dec 2019

HAL is a multi-disciplinary open access archive for the deposit and dissemination of scientific research documents, whether they are published or not. The documents may come from teaching and research institutions in France or abroad, or from public or private research centers.
L'archive ouverte pluridisciplinaire HAL, est destinée au dépôt et à la diffusion de documents scientifiques de niveau recherche, publiés ou non, émanant des établissements d'enseignement et de recherche français ou étrangers, des laboratoires publics ou privés. 


\title{
Architecture for Digital Spare-Parts Library: Use of Ad- ditive Layer Manufacturing in the Petroleum Industry
}

\author{
R.M. Chandima Ratnayake ${ }^{1}$, Arvind Keprate ${ }^{2}$ and Roman Wdowik ${ }^{3}$ \\ ${ }^{1}$ Department of Mechanical and Structural Engineering and Materials Science, \\ University of Stavanger, N4036, Stavanger, Norway. \\ chandima.ratnayake@uis.no \\ ${ }^{2}$ Arvind Keprate \\ DNVGL, Høvik, 1363, Norway.
}

${ }^{3}$ Rzeszów University of Technology, The Faculty of Mechanical Engineering and Aeronautics, 35 959 Rzeszów, Poland

\begin{abstract}
Spare parts management (SPM) is a typical challenge in the offshore and onshore petroleum industry. SPM consumes a significant amount of operational expenses that are attributed to maintaining the integrity of production and process facilities (P\&PFs) at the anticipated level. Productive SPM approaches are essential for maintaining integrity; in particular, ageing P\&PFs and legacy assets exacerbate the challenge of maintaining integrity at the anticipated level. This manuscript firstly provides an overview of how additive layer manufacturing/three-dimensional (3D) printing has been effectively utilized by different manufacturers to produce equipment, which resembles the equipment used in the petroleum industry. Then, it discusses the potential use of a digital spare parts library and the optimal strategy to mitigate current challenges pertaining to SPM. Finally, it proposes an architecture for a digital spare-parts library.
\end{abstract}

Keywords: Spare Parts Management, Petroleum Industry, Three-dimensional Printing, Digital Spare Parts Library.

\section{Introduction}

Additive layer manufacturing (ALM) \{or the buzz term 'three-dimensional printing' (3DP) \} was originally used for prototyping; however, it is now more and more applied to manufacturing end products $[1,2]$. It has been estimated that ALM has the potential to generate an economic impact of $\$ 230$ billion to $\$ 550$ billion per year by 2025 , through direct manufacturing and the use of 3DP to create tools and molds [3]. In some cases, ALM has been considered a supplement to conventional production technologies. In other cases, it is the only means through which complex products can be fabricated [1]. A further distinguishing feature of ALM is its distribution nature. On-site manufacturing for maintenance becomes an important application of ALM. While traditional manufacturing mostly takes place at a centralized facility, with the resulting parts distributed to end users, ALM has the potential for implementation at the point-of-use. It enables innovations in manufacturing value chains, many of which are still being realized [4]. In particular, the petroleum industry seems 
to have benefits when it comes to preserving the integrity of legacy assets. Especially, unprecedented levels of mass customization, smaller and cheaper supply chains, and the 'democratization' of manufacturing, enable the integrity of legacy assets to be maintained (i.e. particularly by allowing clients to print their own spare parts) in the petroleum industry. Hence, it is essential to investigate how to integrate ALM into petroleum-industry-related activities, to transform the effectiveness of upstream supply chains, as well as to bring new markets and sources of revenue to the downstream businesses.

The technology for ALM has been advanced through a coordinated development focusing on three areas (Fig. 1): 3D printers and printing methods [5], software for product design and print [6], and the development of materials for ALM [7]. The use of ALM in the digitalized and automated process chains of spare parts in petroleum industry seems to be one of the most significant opportunities (Fig. 2).

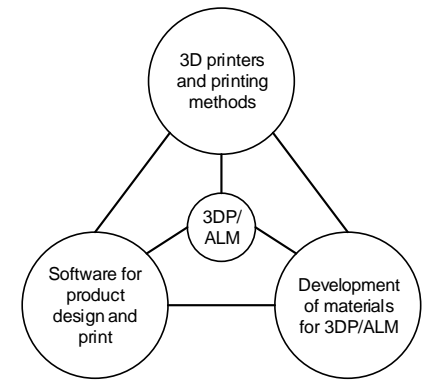

Fig. 1. Three areas of 3DP/ALM.

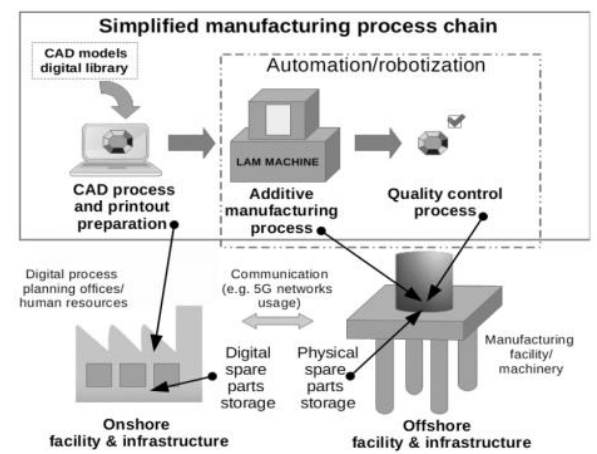

Fig. 2. On-site implementation of ALM.

This paper focuses on investigating how the petroleum industry should plan for the widespread adaptation of ALM, focusing on spare parts. In this context, it discusses whether to go for in-house manufacturing or to outsource it to ALM service providers, as well as examining the impact of ALM on the traditional supply chains vs. the potential for having digital and/or more refined supply chains. It also proposes a framework to reinforce decision-making related to the use of ALM in the petroleum industry.

\section{Challenges Facing Application of ALM in Petroleum Industry}

It is a significant challenge to manage all assets effectively in a predictive manner within the petroleum (i.e. oil and gas), power, energy and process industries, including utilities, petrochemicals and metals and mining [7]. A recent survey reveals that, out of 83 respondents, 53\% report that it is necessary to reduce operational expenses and $40 \%$ state that dealing with ageing assets and infrastructures poses a challenge [7]. The aforementioned survey also reveals that it is important to invest in technology to enhance the management of maintenance projects [7].

The primary objective of a maintenance project is to enhance asset reliability and performance and to minimize the non-productive downtime. In this context, project performance plays a key role, as better project performance reduces the duration of the shutdown of equipment for complex and routine work [7]. It has also been revealed that there is a $6 \%$ 
increase in the shutdown duration in complex maintenance projects, whilst budgetary restrictions prevent asset owners spending on the upgrade or repair/replacement of equipment. The situation has been further exacerbated in the context of maintaining ageing equipment.

In particular, the parts related to legacy assets cause a significant challenge when the manufacturers are no longer in business. In this context, ALM offers the opportunity to print parts that are required to maintain and/or replace equipment as it becomes legacy [8]. Furthermore, the inherent characteristics of ALM provide significant benefits to the petroleum industry, especially when it is necessary to manufacture complex parts that use expensive materials and are required to be made in small batch sizes [8]. Moreover, ALM has an interesting potential for the offshore petroleum industry, as it can mitigate some of the challenges pertaining to the remoteness of offshore from machine shops and skilled labor. For instance, one of the long-term holy grails of ALM is the potential to manufacture parts on site as needed, instead of having to order and wait for delivery when equipment breaks, and spare parts are not available (refer to Fig. 2).

Spare part management and holding inventory increase operational expenses; as 3DP/ALM requires no complex tooling, it is possible to bring the manufacturing nearer to the ultimate consumer, something which is referred to as 'distributed manufacture' (i.e. "migration of manufacturing from the centralized factory to more localized distributed factories") [9]. Moreover, 3DP/ALM reduces many stages of the traditional supply chain, making it leaner via a reduction in the need for haulage, warehousing, logistics and unnecessary expenses on disposable packaging [9].

\section{ALM: Offshore Petroleum Industry Opportunities}

Table 1 illustrates the pros and cons of ALM in industrial applications $[9 ; 10]$.

Table 1. Pros and cons of ALM.

\begin{tabular}{|c|c|}
\hline Pros & Cons \\
\hline $\begin{array}{l}\text { Economical product customization: } \\
\text { - Permits cost-effective production of very small batches. } \\
\text { Allows every single product to be tailor-made to the cus- } \\
\text { tomer's exacting specifications (i.e. significantly difficult } \\
\text { with traditional production processes, as it is necessary to } \\
\text { have expensive tooling and molds, whilst redesign becomes } \\
\text { expensive). }\end{array}$ & $\begin{array}{l}\text { Limited product dimensions: } \\
\text { - Limits the maximum dimensions of } \\
\text { the final product due to relatively } \\
\text { small 3D print bed sizes. } \\
\text { - Need to manufacture large products } \\
\text { by other technologies. }\end{array}$ \\
\hline $\begin{array}{l}\text { Freedom of design: } \\
\text { - Allows for freedom of design because standard CAD soft- } \\
\text { ware can be used to design and redesign products. } \\
\text { - Allows a CAD model to be printed directly into a physical } \\
\text { part, whilst allowing redesigns to be implemented with ease. } \\
\text { - Permits designs to be created by anyone skilled in computer- } \\
\text { aided design. }\end{array}$ & $\begin{array}{l}\text { Reduced choice of materials: } \\
\text { - The limited number of raw materials } \\
\text { that can be used for 3D printing lim- } \\
\text { its the choice of materials, colors, } \\
\text { and surface finish, compared to sub- } \\
\text { tractive technologies. }\end{array}$ \\
\hline
\end{tabular}




\begin{tabular}{lc}
\hline Pros & Cons \\
\hline
\end{tabular}

Complex product manufacturing:
- Enables relatively easy manufacturing of products that were hard or even impossible to produce in the traditional way.

- Allows printing complex products as a single entity at once, resulting not only in less waste and in lighter products but also in time savings with improved performance.

- Reduces overall manufacturing time for complex products, due to the ability to consolidate several machining steps into a single manufacturing step.

Decentralized manufacturing:

- Allows the products designed in standard CAD software environments to be produced anywhere around the world, provided that compatible 3D printers are available (AMplatform, 2014).

- Brings the manufacturing process physically closer to clients, as 3D printers are spreading around the world.

- Reduces time-to-market and/or lead times, as it is possible to outsource manufacturing for globally dispersed 3-D printing service providers.

\section{Lower accuracy level:}

- 3DP/ALM technologies have not yet reached the same level of parts' accuracy associated with other technologies.

Limited strength:

- Due to the layered additive process, products have limited strength, restrained resistance to heat and moisture, and compromised color stability.

In the petroleum industry, there are unique challenges, especially in relation to maintenance and spare parts' management. Figure 3 illustrates different aspects of spare parts in relation to ALM and the corresponding pros and cons.

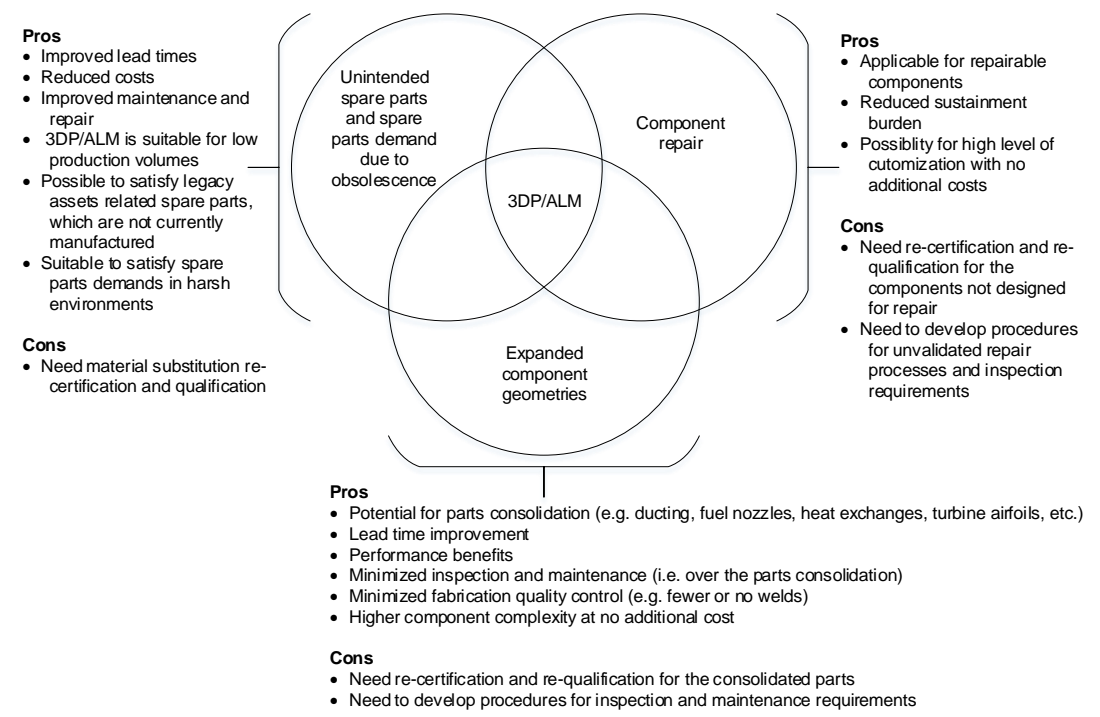

Fig. 3. ALM vs. maintenance and spare parts.

Besides maintenance and spare parts' management challenges, another significant challenge is the dearth of additive manufacturing standards, due to which companies conduct their own testing to ensure the integrity of equipment, processes and products [4]. Costly and time-consuming testing deters the wider application of additive manufacturing, underscoring the need to develop standards from design to part build to operation. Hence, one of the most serious hurdles to the broad adoption of additive manufacturing of materials in the 
petroleum industry is the qualification and certification guidelines for additively manufactured parts. Some of the challenges related to qualification and certification of ALM processes and components are [4]:

- There is a lack of information related to material properties, and we have much less experience and scientific knowledge of ALM processes than of conventional manufacturing.

- Risk assessment based on the statistics of large-volume history data does not apply to ALM production as it does for conventional manufacturing.

- The ALM process has a more disintegrated processing route, compared to conventional manufacturing. Hence, a global traceability solution, enclosing multiple ALM and supply chain locations, will be needed more than ever.

- Secrecy about technology and software/algorithm sources is an obstacle. Since software plays an important role in product quality, it is a subject of concern for certification.

- Directionality and heterogeneity of ALM products can bring challenges for certification and testing.

- Lack of product reproducibility and uncertainty of quality control still exist.

\section{$4 \quad$ ALM vs. Technology Qualification}

The renewal and/or extension of existing technologies and the ability to take advantage of new technologies play a major role in remaining competitive and improving system efficiencies in the petroleum industry [11;12]. In this context, it is a challenging task to confirm that new technological solutions are fit for purpose and that a system will perform as intended during its service life without potential failures [13]. In such situations, the concept of technology qualification identifies opportunities to improve system design, minimize schedule risk, reduce cost risks during operations by reducing uncertainties and increasing reliability, and identify failure modes and necessary design changes at an early stage [14; $15 ; 16]$. Therefore, it is of prime importance to implement a technology qualification process when there is: limited experience about new technology; limited records of accomplishment of novel technologies; absence of classification rules, statutory requirements and industrial standards; and challenges with new and harsh environments [14; 16]. The core idea of the technology qualification process is to identify potential failure modes and the risk of potential failures at an early stage, prior to utilizing a new technology. Hence, it is possible to use recommended practice - DNV-RP-A203 - for qualifying ALM applications in the petroleum industry $[17 ; 15]$.

\section{Framework for Petroleum Industry: A Digital Spare Parts Library}

The competitiveness of the petroleum industry is directly or indirectly affected by the productivity of the maintenance strategy that has been employed. In this context, having a preventive maintenance program (PM) is vital to minimize major repairs and abrupt stoppages of production and to sustain the continuous workflow [18]. Spare parts play a significant role in implementing a PM program, and the previous sections in this manuscript have revealed that ALM has a higher potential to cater for spare-parts-related challenges. However, it is also essential to investigate the manufacturing operational challenges such as "parameter design' [19]. In this context, the 'parameter design' involves investigating the opti- 
mal parameter combination that provides the required output performance in the ALM process. The aforementioned is crucial for ALM, due to its inherent suitability, such as the manufacturing of complex parts that use expensive materials with small batch sizes together with a high level of customization. It is impossible for the ALM machine manufacturer to develop a user manual, which caters for different product manufacturing demands. For instance, [20] demonstrated an investigation of the process parameter effects on the dimensional accuracy of parts produced by the Polyjet Direct 3D printing process. Hence, it is possible to use an engineering robust design approach, as indicated in [19], for 3DP/ALM 'parameter design', in order to align with lean manufacturing philosophies (i.e. minimization of waste in relation to time and other resources). It is possible to make the transition from a physical spare parts inventory to a digital spare parts library with 3DP/ALM capabilities [17]. In this context, it is vital to develop a group technology (GT) based coding system to retrieve spare-parts-related information from a digital library for performing ALM work just-in-time [20;18;21]. Fig. 4 illustrates an architecture for a spare parts library, focusing on 'prioritization of spare parts', 'parameter designing', and 'group technology' (GT), for effective exploitation of ALM in the petroleum industry.

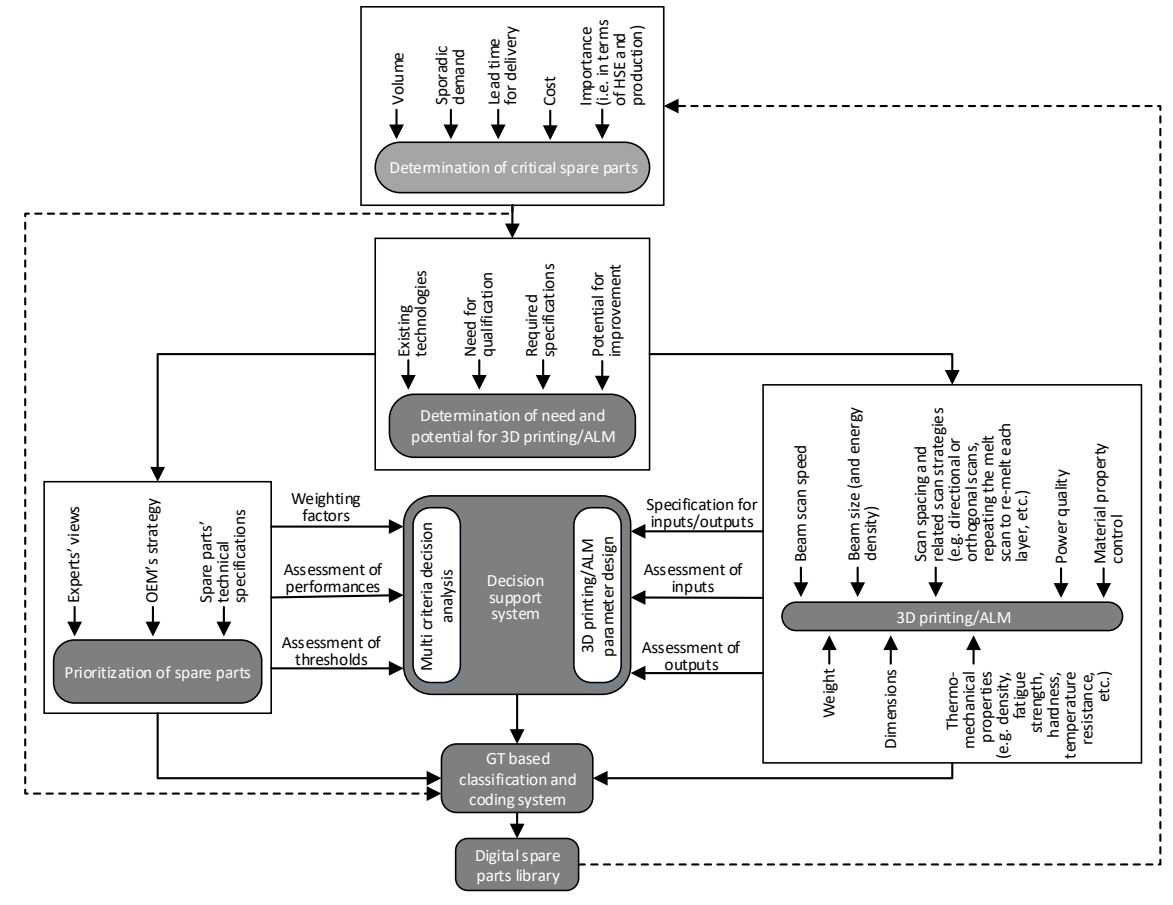

Fig. 4. Architecture for digital spare parts library.

For instance, [18] have proposed a GT-based approach to optimize the inventory of spare parts, using a "failure similarity coefficient (FSC)", which "defines the relationship between pairs of equipment/machines with respect to their needs for PM based on the type of failures they encounter". In addition, [21] demonstrated the use of GT-based classification and grouping according to the principle and structure of the new equipment and new spare parts. Moreover, [22] have demonstrated the use of the "Vector Perturbation Approach" for addressing the aircraft spare parts' grouping problem. 


\section{Conclusion}

The study presented in this manuscript has demonstrated the role of ALM and its potential for use in the offshore petroleum industry. It showed the importance of the development of three areas: 3D printers and printing methods, materials for ALM, and software for product design and print. It also presented the need to invest in technologies to better manage maintenance projects and the role of ageing equipment (requiring additional maintenance). In addition, it explained how ALM fits within advanced manufacturing performance, as well as focusing on mitigating maintenance and spare parts' challenges. Furthermore, the potential use of a technology qualification process for assuring the use of additive layer manufactured parts has been explained. Finally, it proposed an architecture for a 'spare parts library', demonstrating the interrelationship among: 'determination of critical spare parts', 'prioritization of spare parts', 'parameters involved in 3DP/ALM', 'determination of need and potential for 3DP/ALM', 'GT-based classification and coding system', and 'multi-criteria analysis for decision-making accompanied by parameter design' for enhancing the potential use of ALM in the petroleum industry.

Future research shall be carried out to investigate the effective use of risk-based prioritization of spare parts, accompanied by artificial intelligence/machine learning supported group technology, focusing on developing methodologies for effective parameter designing, to enhance the use of ALM, mitigating spare-parts-related challenges.

Acknowledgement: The study was partly carried out within the project, "Science internship for the investigations of digitalization in manufacturing", financed by the Polish National Agency for Academic Exchange in the Bekker Programme.

\section{References}

1. Janssen, R., Blankers, I., Moolenburgh, E., Posthumus, B.: TNO: The impact of 3D printing on supply chain management (2014). http://3din.nl/wp-content/uploads/2014/02/TNOWhitepaper-3-D-Printingand-Supply-Chain-Management-April-2014-web.pdf, last accessed 2016/04/10.

2. Campbell, T., Williams, C., Ivanova, O., Garrett, B.: Could 3D printing change the world? Technologies, and implications of additive manufacturing. Atlantic Council, Washington DC, USA (2011).

3. EU: Working Paper: Digital economy facts \& figures. Experts Group on Taxation on Digital Economy (2014). http://ec.europa.eu/taxation_customs/ resources/documents/taxation/gen_info/goodgovernancematters/digital/2014-03-13factfigures.pdf, last accessed 2015/04/10.

4. DNVGL-CG-0197: Additive manufacturing - qualification and certification process for materials and components, Class Guideline. DNVGL (2017). http://rules.dnvgl.com/docs/pdf/DNV/codes/docs/2013-07/RP-A203.pdf, last accessed 2019/01/04.

5. Earls, A., Baya, V.: The road ahead for 3-D printers. (2014). http://www.pwc.com/us/en/technology-forecast/2014/issue2/features/future-3d-printing.html, last accessed 2016/04/08.

6. Berman, B.: 3-D printing: The new industrial revolution. Business Horizons 55(2) 155$162(2012)$.

7. Aberdeen-Group: Project management practices for asset maintenance: A Guide for power, energy \& process industries (2010). http://www.oracle.com/us /products/ applications/ primavera/ sector-insight-report-193055.pdf, last accessed 2016/04/08. 
8. Boman, K.: What kind of potential does 3D printing hold for oil, gas? (2015). http://www.rigzone.com/news/oilgas/a/141296/WhatKindofPotentialDoes3DPrintingHoldforOilGas/?all=HG2, last accessed 2016/04/08.

9. Reeves, P.: Additive manufacturing-A supply chain wide response to economic uncertainty and environmental sustainability. Econolyst Ltd., Derbyshire, UK (2008). http://www.econolyst.co.uk/resources/documents/files/Paper 2008AMasupplychainwideresponse.pdf, last accessed 2015/12/26.

10. Wohlers, T.: Wohlers report 2012 - Additive manufacturing and 3D printing state of the industry: Annual worldwide progress report. 2012 edition, Wohlers Associates, Colorado, USA (2012).

11. Shehabuddeen, N., Probert, D., Phaal, R.: From theory to practice: Challenges in operationalizing a technology selection framework. Technovation 26(3) 324-335 (2006).

12. Samarakoon, S.M.S.M.K., Ratnayake, R.M.C.: Improving efficiency of technology qualification process in industrial sectors. International Journal of Continuing Engineering Education and Life-Long Learning 24(3/4) 362-376 (2014).

13. Samarakoon, S.M.S.M.K., Gudmestad, O.T.: The IPPC directive and technique qualification at offshore oil and gas installations. Journal of Cleaner Production 19(1) 13-20 (2011).

14. Ratnayake, R.M.C.: Enabling RDM in challenging environments via additive layer manufacturing: Enhancing offshore petroleum asset operations. Production Planning \& Control 30(7) 522-539 (2019).

15. DNVGL-RP-A203: Technology qualification, recommended practice. Det Norsk Veritas AS (2013). http://rules.dnvgl.com/ docs/pdf/DNV/codes/docs/2013-07/RP-A203.pdf, last accessed 2016/01/04.

16. Levett, B.A., Brandt, H.: The role of risk management in development and application of new technology. SPE/IADC Drilling Conference - Drilling Technology Amsterdam (Netherlands):92643-MS (2005).

17. Ratnayake, R.M.C.: Making sense of 3D printing/additive layer manufacturing in offshore petroleum industry: State of the art. In: Proceedings of ASME 2016 35th International Conference on Ocean, Offshore and Arctic Engineering (OMAE2016), BEXCO Exhibition \& Convention Center, Busan, South Korea, OMAE2016-54537 (2016).

18. Almomani, M., Abdelhadi, A., Seifoddini, H., Xiaohang, Y.: Preventive maintenance planning using group technology: A case study at Arab Potash Company, Jordan. Journal of Quality in Maintenance Engineering 18(4) 472-480 (2012).

19. Ratnayake, R.M.C., Valbo, I.: Use of robust design technique in job shop manufacturing: A case study of die-sinking electro discharge machining. International Journal of Performability Engineering 10(2) 153-160 (2014).

20. Kechagias, J., Stavropoulos, P., Koutsomichalis, A., Ntintakis, I., Vaxevanidis, N.: Dimensional accuracy optimization of prototypes produced by PolyJet direct 3D printing technology. International Conference on Industrial Engineering (INDE '14), Santorini Island, Greece, July 17-21 (2014).

21. Li, Q., Tian, Z.: The demand forecast of spare parts based on group technology. In: Proceedings of 4th International Conference on Wireless Communications, Networking and Mobile Computing, 10.1109/WiCom.2008.1586 (2008).

22. Samatova, N.F., Potok, T.E., Leuze, M.: A vector perturbation approach to the generalized aircraft spare parts grouping problem. In: Proceedings of the 10th International Conference on Flexible Automation and Intelligent Manufacturing, pp. 1017-1026 (2000). http://web.ornl.gov/ webworks /cpr/pres/105333.pdf, last accessed 2016/04/15. 